\title{
International Coconut Genetic Resources Network (COGENT): Its history and achievements
}

\author{
Pons Batugal $^{1}$
}

\begin{abstract}
The International Coconut Genetic Resources Network (COGENT) is a global research network organized by the International Plant Genetic Resources Institute (IPGRI) in 1992 with support from member countries, the Consultative Group on International Agricultural Research (CGIAR), partner institutions, donor agencies, and by regional and international development organizations.

In the last 12 years, COGENT has been fully operational with 38 member coconut producing countries in five regions (South Asia; Southeast and East Asia; South Pacific; Africa and the Indian Ocean; and Latin America and the Caribbean). It has successfully developed and disseminated to coconut breeders and curators worldwide the International Coconut Genetic Resources Database (CGRD). The CGRD contains characterization data and some pictures of 1,416 accessions which are conserved by national programmes in 28 sites in 23 countries. To further secure conserved germplasm, a COGENT multi-site International Coconut Genebank has been established to conserve 200 important accessions in each region. Coconut varieties with multi-purpose uses are being identified, documented and promoted. The performance of promising 38 high-yielding hybrids are being evaluated in a multilocation trial involving four African and three Latin America/Caribbean countries to identify suitable varieties and hybrids for resource-poor farmers. Farmers' varietal preferences in 15 countries are being evaluated. Diversity-linked incomegenerating activities are being used as a strategy to promote in situ and on-farm conservation and germplasm utilization have been initiated in 15 countries. Protocols for in vitro embryo culture, cryopreservation, morphometric and molecular marker-based methods for locating and characterizing diversity; pest risk assessment and germplasm health management are being developed, tested and upgraded. Strategies and techniques for farmer participatory research, collecting, characterization and ex situ and in situ conservation are being refined.

To strengthen the coconut research capability of COGENT member countries, the COGENT Secretariat and IPGRI have organized 39 country need assessment missions and conducted 41 workshops and meetings involving 994 coconut researchers to share information and technologies, discuss issues and common problems and opportunities and how to address them; conducted 40 training courses involving 765 participants from 41 countries; supported 274 research and training/capacity building activities in 30 countries; and led the establishment of the Global Coconut Research for Development Programme (PROCORD). IPGRI and COGENT's current priority involves the further promotion of more effective conservation and use of coconut genetic resources, both regionally and globally.
\end{abstract}

Key words: COGENT, coconut, germplasm, conservation, genebank, database.

\footnotetext{
${ }^{1}$ Senior Scientist and COGENT Coordinator, International Plant Genetic Resources Institute (IPGRI).
} 


\section{Introduction}

The possibility of an international initiative in coconut research was first discussed with the Asian and Pacific Coconut Community (APCC) at its meeting in Bangkok in May 1989 and at a subsequent meeting in Singapore later that year. At about the same time, the Technical Advisory Committee (TAC) was tasked by the Consultative Group on International Agricultural Research (CGIAR) to undertake a consultative process to identify: 1) priority problems that affect coconut production; 2) those problems that could be addressed through research; 3) new approaches to address those researchable issues that are international in character and beyond the scope of any one country to resolve. The priorities identified for international effort were: 1) germplasm collecting, conservation, evaluation and enhancement; 2) pests and diseases control, especially the lethal diseases; 3) improving productivity and sustainability of coconut-based systems; 4) increasing efficiency and addition value in post harvest handling and utilization; and 5) addressing socioeconomic issues, such as the factors that influence farmers' choices in replanting coconut land.

On 8-11 October 1991, the International Board for Plant Genetic Resources or IBPGR (renamed International Plant Genetic Resources Institute or IPGRI in 1992) organized an international workshop on coconut genetic resources in Cipanas, Indonesia involving leading coconut researchers from 15 countries. The workshop participants recommended that an international coconut genetic resources network be established with IBPGR serving as the executing agency for Phase I (first five years) of this network and nominated the initial members of the Steering Committee. Based on the results of the TAC consultation process, the CGIAR decided to include coconut in its research portfolio in 1992 after studies indicated that international support and global coordination of research in coconut is essential to make it more productive and beneficial to smallholder coconut farmers. The CGIAR and TAC recognized that international support to coconut research was needed as many coconut-producing countries lacked both the human and material resources to conduct expensive and time-consuming research. Thus, it tasked IPGRI (then IBPGR). To undertake research on coconut genetic resources which was one of the five identified priority research areas that deserved international support. Accordingly, IPGRI included coconut genetic resources in its plant genetic resources research programme and organized the International Coconut Genetic Resources Network (COGENT) to implement this mandate. Dr Gabrielle Persley, then working with the Australian Centre for International Agricultural Research (ACIAR), and later with the Doyle Foundation, is credited with making a major contribution to COGENT for supporting case studies and organizing efforts to convince the CGIAR that coconut research need international support; in commissioning external reviews to evaluate the progress of COGENT and in developing its strategic plan; and in organizing the CGIAR Coconut Support Group to generate support for COGENT priority activities. To organize COGENT, IPGRI engaged Dr Hugh Harries as a Consultant in 1991 who helped develop the first five-year work plan and who eventually suggested the acronym 'COGENT' for the network. Mr Gerardo Santos served as the Acting Coordinator of COGENT for a few months in early 1993. Dr Michel de Nuce followed briefly as Coordinator for the rest of 1993. From thereon, Dr. Pons Batugal served as Coordinator for the last 11 years, i.e. from 1994 to date. Starting with the 15 countries that participated in the Cipanas workshop, COGENT has rapidly developed into an active global Network currently involving 38 coconut producing countries (Table 1).

\section{COGENT's goal, objectives and organizational structure}

COGENT's goal is to improve coconut production on a sustainable basis and increase incomes in developing countries, through improved cultivation of the coconut and efficient utilization of its products and byproducts. The objectives of COGENT are to: 1 ) 
establish and maintain an international coconut database on existing and future germplasm collections; 2) encourage the protection and use of existing germplasm collections; 3 ) identify and secure additional threatened diversity by developing and adopting suitable technologies and conservations strategies; 4) promote greater collaboration among research groups in producer countries and advance technology sources in the exchange of germplasm and the development of new conservation techniques; 5) conduct appropriate training, information dissemination; and 6) secure necessary funding for network activities. To achieve this goal, COGENT organized its Steering Committee (SC) with two representatives from each geographical region, the Executive Director of the APCC and the COGENT Coordinator who serve as non-voting members, with the latter also serving as SC Secretary. Five sub-regional/regional networks were also organized: South Asia; Southeast and East Asia; South Pacific; Africa and the Indian Ocean; and Latin America and the Caribbean (Table 1). Each member country designates an experienced coconut scientist as COGENT Country Coordinator to coordinate all COGENT supported projects in the country, and a Project Leader for every COGENT-supported project or activity that the country undertakes.

IPGRI continues to be the executing agency for COGENT and provides funding for the secretariat and technical and administrative support. The SC decides on the priority research and training activities. In 1995, Dr Persley organized the CGIAR Coconut Support Group, comprised of donors and partner institutions, which reviews the identified priority projects of COGENT for possible funding support.

\section{Achievements in the last 12 years}

\section{International Coconut Genetic Resources Database (CGRD)}

To equip member countries with relevant information and technologies for coconut research, COGENT, in collaboration with CIRAD and with funding from the French Government from 1996 to 2003, developed the CGRD. To date, it contains the passport and characterization data (including some molecular marker data and pictures) of 1,416 coconut accessions worldwide (Table 2). CIRAD has incorporated in the CGRD and its associated software, a management system endowed with functions that can be used to carry out all the necessary operations on the data it contains. Individual countries can now update their database as they generate data from their genebank collections. This database helps coconut breeders to effectively select materials for developing improved varieties.

\section{Conservation in national coconut genebanks}

World coconut production is declining due to ageing palms, natural calamities, inadequate replanting programme, lack of suitable planting materials, poor crop management, population pressures causing crop shifts, and lack of capital for farmers to invest in coconut production. The development and use of improved coconut cultivars can markedly help solve these problems and promote increased coconut production. However, the landraces of coconut (ecotypes), which contain important genetic characters for yield, disease and pest resistance and adaptation, are under threat of genetic erosion and need to be collected, conserved, evaluated and shared more widely to develop improved varieties.

Under the Asian Development Bankfunded project (1998-2000), an additional 541 coconut populations were collected in 20 Asia Pacific countries and these were conserved in 16 national coconut genebanks. The conserved accessions are currently being evaluated and characterization data are registered in the CGRD.

Globally, COGENT supported member countries and partner institutions to conserve and upgrade 1,416 accessions in national coconut genebanks and collections in 28 sites in 23 countries (Table 2). These collections include coconut genetic resources collected in respective countries and introduced from other countries which have potential use in developing improved varieties. Some of these 
Table 1. COGENT member countries

\begin{tabular}{|l|l|l|l|l|}
\hline \multicolumn{1}{|c|}{$\begin{array}{c}\text { Southeast and } \\
\text { East Asia }\end{array}$} & \multicolumn{1}{|c|}{ South Asia } & \multicolumn{1}{|c|}{ South Pacific } & \multicolumn{1}{c|}{$\begin{array}{c}\text { Africa/Indian } \\
\text { Ocean }\end{array}$} & \multicolumn{1}{c|}{$\begin{array}{c}\text { Latin America/ } \\
\text { Caribbean }\end{array}$} \\
\hline 1. China & 1. Bangladesh & 1. Cooke Is. & 1. Benin & 1. Brazil \\
2. Indonesia & 2. India & 2. Fiji & 2. Cote d'Ivoire & 2. Colombia \\
3. Malaysia & 3. Pakistan & 3. Kiribati & 3. Ghana & 3. Costa Rica \\
4. Myanmar & 4. Sri Lanka & 4. Papua New & 4. Kenya & 4. Cuba \\
5. Philippines & & Guinea & 5. Madagascar & 5. Guyana \\
6. Thailand & & 5. Solomon Is. & 6. Mozambique & 6. Haiti \\
7. Vietnam & & 6. Tonga & 7. Nigeria & 7. Honduras \\
& & 7. Vanuatu & 8. Seychelles & 8. Jamaica \\
& & 8. Samoa & 9. Tanzania & 9. Mexico \\
& & & & 10. Trinidad \& Tobago \\
\hline
\end{tabular}

germplasm have important traits for the production of high-value products or for the development of high-value varieties, i.e. high-oil content, aromatic, good tendernut flavor, softendosperm, high-sap content, big-sized nut, thick shell and high-husk content, and resistance to drought and diseases. It is imperative that these varieties are conserved on-farm and used, as they are the basis for sustainable coconut production.

Since its establishment, COGENT has helped its member countries upgrade and evaluate their collections and the new accessions that have been collected under the auspices of the ADB-funded project. The publication of the COGENT Standardized Research Techniques in Coconut Breeding or STANTECH manual (Santos et al., 1996) has greatly facilitated much desired order into the collections and the streamlining of their management. In the past, lack of well trained coconut researchers had hampered coconut germplasm conservation and use. This constraint was addressed through two STANTECH regional trainers' courses, which included several aspects of field genebank management.

\section{Conservation in COGENT's Multi-site International Coconut Genebank}

While national coconut field genebanks are important sources of germplasm for exchange among COGENT member countries, many countries do not have the capacity to maintain their conserved germplasm due to lack of economic and technical capacity. Second, many countries do not have the capacity to evaluate the agronomic performance of their germplasm and if ever there were evaluation trials, data obtained are often not comparable. Third, multi-country negotiations for obtaining germplasm are often difficult for national breeding programmes that would like to import germplasm that belong to several countries. Fourth, many researchers who may want to share their germplasm do not have the needed policy cover and their countries lack the facilities for ensuring the safe movement of coconut accessions.

To provide double security for conserved germplasm in national genebanks and to promote effective access and safe germplasm movement, the COGENT Steering Committee decided to establish a multi-site International Coconut Genebank (ICG) in 1995, consisting of regional genebanks hosted by India for South Asia, Indonesia for Southeast and East Asia, Papua New Guinea for the South Pacific and Côte d'Ivoire for Africa and the Indian Ocean. Negotiations are underway for Brazil to host the ICG for Latin America and the Caribbean (Rao and Batugal, 1994). To date, 224 accessions have been conserved (Table 3). These collections are part of the international ex situ 
Table 2. COGENT's International Coconut Genetic Resources Database

\begin{tabular}{|c|c|c|c|c|c|}
\hline Site & $\begin{array}{l}\text { Number of } \\
\text { accessions }\end{array}$ & $25<P=75$ & $25<E=75$ & $\begin{array}{c}\text { With } \\
\text { pictures }\end{array}$ & $\begin{array}{c}\text { With } \\
\text { molecular } \\
\text { data }\end{array}$ \\
\hline $\begin{array}{l}\text { CNRA Marc Delorme Research Station, Port- } \\
\text { Bouët, Côte d'Ivoire } \\
\text { Coconut Programme, OPRI, Sekondi, Ghana } \\
\text { CRC, Sémé Podji, Benin } \\
\text { National Coconut Development Programme, Dar } \\
\text { Es Salaam, Tanzania }\end{array}$ & $\begin{array}{c}99 \\
16 \\
4 \\
\\
72\end{array}$ & $\begin{array}{l}4 \\
71\end{array}$ & $\begin{array}{c}71 \\
4 \\
4 \\
69\end{array}$ & $\begin{array}{c}73 \\
15 \\
4 \\
\\
35\end{array}$ & $\begin{array}{c}67 \\
14 \\
3 \\
33\end{array}$ \\
\hline African Region & 191 & 103 & 148 & 127 & 117 \\
\hline $\begin{array}{l}\text { Centro de Investigacion Cientifica de Yucatan, } \\
\text { Merida, Mexico } \\
\text { Coconut Industry Board, Kingston, Jamaica } \\
\text { EMBRAPA, Aracaju, Betume-Brazil }\end{array}$ & $\begin{array}{l}20 \\
60 \\
16\end{array}$ & $\begin{array}{l}20 \\
16 \\
16\end{array}$ & $\begin{array}{c}1 \\
58 \\
16\end{array}$ & $\begin{array}{c}1 \\
32 \\
10\end{array}$ & $\begin{array}{c}2 \\
36 \\
10\end{array}$ \\
\hline Latin America-Caribbean Region & 96 & 52 & 75 & 43 & 48 \\
\hline $\begin{array}{l}\text { BARI, Gazipur, Bangladesh } \\
\text { Coconut Research Institute, Lunuwilla, Sri Lanka } \\
\text { CPCRI, Kasaragod, India } \\
\text { RS, Islamabad, Pakistan }\end{array}$ & $\begin{array}{c}40 \\
78 \\
212 \\
32\end{array}$ & $\begin{array}{c}18 \\
78 \\
141\end{array}$ & $\begin{array}{c}37 \\
64 \\
211\end{array}$ & $\begin{array}{c}5 \\
76\end{array}$ & $\begin{array}{l}10 \\
52\end{array}$ \\
\hline South Asian Region & 362 & 237 & 312 & 81 & 62 \\
\hline $\begin{array}{l}\text { Cocoa and Coconut Research Institute, Rabaul, } \\
\text { Papua New Guinea }\end{array}$ & 3 & & 3 & 5 & 30 \\
\hline $\begin{array}{l}\text { Stewart Research Station, Madang, Papua New } \\
\text { Guinea }\end{array}$ & 54 & 31 & 54 & 3 & 2 \\
\hline Ministry of Agriculture, Nuku'alofa, Tonga & 7 & & 1 & 2 & 2 \\
\hline Saraoutou Research Station, Santo, Vanuatu & 79 & 71 & 11 & 48 & 53 \\
\hline Taveuni Coconut Centre, Taveuni, Fiji & 11 & 8 & 7 & 5 & 5 \\
\hline Olomanu Coconut Seed Garden, RS, Apia, Samoa & 9 & & 9 & 4 & 3 \\
\hline RS, Yandina, Solomon Islands & 21 & 4 & 21 & 10 & 11 \\
\hline South Pacific Region & 184 & 114 & 106 & 77 & 106 \\
\hline Coconut Research Institute, Wenchang, China & 17 & 15 & 17 & & 14 \\
\hline Department of Agriculture, Sabah, Malaysia & 45 & 23 & 30 & 23 & 19 \\
\hline Mardi, Hilir, Perak \&Terengganu, Malaysia & 44 & 34 & 39 & 40 & 38 \\
\hline $\begin{array}{l}\text { Bone Bone Experimental Garden, Manado, S. } \\
\text { Sulawesi, Indonesia }\end{array}$ & 41 & 35 & 41 & & \\
\hline $\begin{array}{l}\text { Mapanget Experimental Garden, Manado, N. } \\
\text { Sulawesi, Indonesia }\end{array}$ & 74 & 74 & 45 & 14 & 17 \\
\hline $\begin{array}{l}\text { Pakuwon Experimental Garden, W. Java, } \\
\text { Indonesia }\end{array}$ & 25 & 22 & 25 & 8 & 10 \\
\hline $\begin{array}{l}\text { Sikijang Experimental Garden, Pekanbaru, } \\
\text { Indonesia }\end{array}$ & 30 & 30 & 30 & 3 & 5 \\
\hline $\begin{array}{l}\text { Philippine Coconut Authority, Zamboanga, } \\
\text { Philippines }\end{array}$ & 224 & 221 & 219 & 194 & 51 \\
\hline $\begin{array}{l}\text { Chumphon Horticultural Research Centre, } \\
\text { Chumphon, Thailand }\end{array}$ & 52 & 42 & 52 & 9 & 8 \\
\hline $\begin{array}{l}\text { Dong Go Experimental Center, Ben Tre Province, } \\
\text { Vietnam }\end{array}$ & 31 & 30 & 16 & 9 & 8 \\
\hline Southeast Asian Region & 583 & 526 & 514 & 300 & 170 \\
\hline Total for all Regions & 1416 & 1032 & 1155 & 628 & 503 \\
\hline
\end{tabular}

collections under the Undertaking on

International Plant Genetic Resources.
Memoranda of agreements for hosting the ICG have been signed by the hosting country 
governments, IPGRI on behalf of COGENT, and the Food and Agriculture Organization (FAO) of the United Nations serving as trustee.

The four host countries are currently importing additional germplasm from the member countries in their respective regions. These will be grown in vitro in the embryo culture laboratory, raised in the nursery and transplanted in the ICG when ready.

It is envisioned that the ICG for each region will conserve in field genebanks about 200 important accessions. They are being established and managed by the national programs under the oversight of COGENT and IPGRI. With funding from the ACIAR, IPGRI/COGENT has published a Manual on Germplasm Health Management for the COGENT's International Coconut Genebank (Ikin and Batugal, 2004) which will serve as the guide for national genebank managers and the quarantine service.in managing the ICG and the movement of germplasm worldwide.

ICG laboratories and facilities will also be developed and upgraded which will be used to further locate diversity, identify and eliminate duplicates, conduct disease indexing, process pollen and embryos for export, conduct cryopreservation and train coconut researchers from member countries in evaluating, conserving and using germplasm. Thus, the ICGs will be developed as Centers of Excellence as part of the IPGRI intiative on upgrading and capacity building of its partner institutions.

The conserved germplasm in the field genebanks is covered by a Material Transfer Agreement obliging each ICG to provide access to their conserved germplasm to all coconut producing countries, not to patent conserved germplasm and to pass the later obligation to third parties receiving the germplasm. The inclusion of coconut in the list of commodity crops under the International Treaty for Food and Agriculture will further accelerate the sharing of coconut germplasm among the COGENT member countries.

\section{In situ and on farm conservation}

COGENT realizes that despite the intensive efforts on collecting and conserving coconut genetic diversity ex situ, the major part will remain in situ, in the yards or gardens of small-scale farmers, undisturbed tropical sea coasts and uninhabited islands. Many of these farmers' varieties are in danger of being lost resulting in genetic erosion of some of the most adapted and needed germplasm for sustainable coconut production. Thus, COGENT has developed a protocol for genetic erosion study and has pretested it in Sri Lanka, Thailand and Kiribati. Initial results indicated that the threats to genetic erosion, caused by urbanization, shifts to other more profitable crops, calamities such as drought, typhoons, pests and diseases, are real and need to be addressed.

In situ conservation had been previously proposed as a method for conservation as it has the distinct advantage of conserving already adapted germplasm that have naturally evolved in niche environments. COGENT has developed and implemented a diversity-linked "Poverty reduction in coconut growing communities project" that addresses both in situ and on-farm conservation through a farmer participatory approach (Batugal and Oliver, 2004; Batugal and Coronel, 2004; and Batugal and Oliver, 2005). Under this project, three pilot coconut growing communities in each participating country tested the viability of four coconut-based income generating strategies: 1) production and marketing of high-value products from all parts of the coconut; 2) intercropping cash and food security crops, 3) livestock/fodder production; and 4) production and selling of highquality coconut seedlings which are raised in community-managed nurseries. The communitymanaged nurseries propagate seed nuts for onfarm conservation from identified local varieties which are selected based on farmer participatory rapid appraisal of community genetic resources-

Table 3. Germplasm conserved in the International Coconut Genebank 


\begin{tabular}{|l|c|c|c|}
\hline \multicolumn{1}{|c|}{ Name of Genebank } & $\begin{array}{c}\text { Date when MOA } \\
\text { signed }\end{array}$ & $\begin{array}{c}\text { Initial number in } \\
\text { list of } \\
\text { designated } \\
\text { germplasm }\end{array}$ & $\begin{array}{c}\text { Designated } \\
\text { germplasm } \\
\text { currently } \\
\text { conserved* }\end{array}$ \\
\hline $\begin{array}{l}\text { 1. International Coconut Genebank for the } \\
\text { South Pacific (Papua New Guinea) }\end{array}$ & $\begin{array}{c}30 \text { September } \\
1998\end{array}$ & 55 & 50 \\
\hline $\begin{array}{c}\text { 2. International Coconut Genebank for } \\
\text { Southeast Asia (Indonesia) }\end{array}$ & 26 May 1999 & 52 & 29 \\
\hline $\begin{array}{l}\text { 3. International Coconut Genebank for Africa } \\
\text { and The Indian Ocean (Côte d'Ivoire) }\end{array}$ & 14 October 1999 & 49 & 99 \\
\hline $\begin{array}{c}\text { 4. International Coconut Genebank for South } \\
\text { Asia (India) }\end{array}$ & 30 October 1998 & 49 & 46 \\
\hline Total & & $\mathbf{2 0 5}$ & $\mathbf{2 2 4}$ \\
\hline
\end{tabular}

* Additional accessions were added to the initial list of designated germplasm.

(Eyzaguirre and Batugal, 1998) and during coconut diversity fairs. Mother palms of these selected varieties are paint-marked for in situ conservation and as sources of seednuts for propagation. Each project participant in the 24 community pilot models is encouraged to plant at least five seedlings purchased from the communitymanaged nursery per year. Introduced high-value varieties are also propagated in the same nursery to increase the coconut diversity. This ADBfunded project, which was successfully implemented in eight Asia Pacific countries (Bangladesh, India, Sri Lanka, Indonesia, the Philippines, Vietnam, Fiji and Papua New Guinea) from 2002 to 2004, produced 65,505 seedlings from 89 farmers' varieties which were conserved on farm. Initial results indicate that it is a sustainable 'conservation through use' strategy.

\section{Developing strategies and technologies for germplasm conservation and use}

Conservation in field genebanks is the most popular and practical method of ex situ conservation but it is expensive and requires a large land area that many national programmes do not have. Thus, COGENT is supporting the development of complementary conservation strategies and technologies. In 1997, COGENT supported the development of coconut in vitro embryo culture techniques to facilitate collecting and the exchange of materials between partners and make such exchange safe from pests and diseases. A workshop was organized in Albay, Philippines involving eight countries to discuss the status of coconut embryo culture technology and to develop a collaborative research to upgrade the technology (Batugal and Engelmann, 1998). COGENT awarded research grants to 12 countries to upgrade the technology, and in 2001, participants met in a workshop in Merida, Mexico to report on the results of their findings (Engelmann and Batugal, 2002). These research results are published and disseminated to coconut research worldwide.

For long-term conservation, preliminary experiments have led to the development of a cryopreservation protocol, which has been successfully applied to zygotic embryos of four different genotypes. COGENT has collaborated with the International Research for Development (IRD, formerly ORSTOM) and national partners in upgrading the cryopreservation technology and in conducting two cryopreservation workshops to train the coconut researchers on the updated technology. Five coconut researchers were trained in the cryopreservation course at National Board for Plant Genetic Resources (NBPGR) in India in 2002 and another five in a similar course at IRD in Montpellier in 2003. All trainees were required to develop re-entry work plans to validate techniques learned using their local accessions and laboratories. 
The potential of somatic embryogenesis as a tool to promote accelerated coconut germplasm conservation and use has been explored. If successful, it could be used to rapidly multiply identified parent materials to provide adequate number of plants for breeding or replanting by COGENT member countries. Mass propagation by means of somatic embryogenesis was studied and clonal plantlets were produced for some genotypes in a reproducible manner. However, this study, which was funded by the European Union and involving five major advanced laboratories, was initially limited by its low recovery rate of embryos. Nevertheless, the recent report of work on embryo culture of the Centro Investigacion Cientifico de Yucatan (CICY) in Mexico at the Coconut and Oil Palm Biotechnology Meeting in Manila in April 2004 indicated substantial progress. Using improved techniques developed by CICY, it was reported that about 100,000 embryos could be produced from a single plumule. COGENT is arranging for this upgraded technology to be downstreamed to the ICGs, and funding is being sought for the conduct of a workshop to disseminate the upgraded technology for further validation and refinement.

There is a need to develop and use molecular marker methods to characterize coconut germplasm, identify key physiological and agronomic parameters and their interactions with the environment and to tag the desired traits for breeding. This will increase their predictive value in breeding for high-yielding, adapted and high-value varieties. For this purpose, COGENT collaborated with CIRAD in developing molecular marker methods for studying coconut diversity which produced a microsatellite kit, which 10 COGENT member countries are now using to characterize their conserved germplasm and farmers' varieties.

Given these developments, it should not be long before these new technologies can be exploited to complement the field genebanks and in situ/on farm conservation for the medium and long-term conservation of coconut.

\section{Germplasm evaluation}

In 2001, COGENT and BUROTROP supported APCC in conducting a survey on the performance of coconut hybrids and varieties, and farmers' varietal preferences in 10 coconut producing countries. The results showed that: 1) there are no universal hybrids, with each hybrid having their specific niches where it performs well; 2) hybrids performed better than traditional varieties under adequate rainfall and good soil conditions; 3 ) under optimum growing conditions and management, the coconut hybrids tested could produce up to 5 tons of copra per hectare per year compared to the 1-2 tons obtained from traditional varieties and 4) farmers were not interested in high yields per se but also in other characteristics such as low input-requiring varieties and varieties with special characteristics for producing high-value products.

In 1999-2004, COGENT conducted a CFCfunded hybrid multilocation trial involving three African countries (Côte d'Ivoire, Benin and Tanzania) and three Latin American and Caribbean countries (Brazil, Mexico and Jamaica) to identify suitable hybrids and varieties for smallholders. Each of the six countries compared the six common multi-site control hybrids produced and shipped from Côte d'Ivoire with their local hybrids. The .imported test materials were four $\mathrm{D} \times \mathrm{T}$ and two $\mathrm{T} \times \mathrm{T}$ hybrids which have been proven to have good yield potential in other separate trials. Included in each country location trial are 4-8 promising local hybrids/varieties as local control. The Government of Portugal funded a similar project involving the evaluation of the same six multi-site hybrid controls and four local hybrids in Mozambique. This brought to 38 the total number of coconut hybrids (including the local hybrids) being evaluated, making this project the most comprehensive coconut hybrid trial worldwide.

The most important result of the project is the identification of 19 early bearing and highyielding new coconut hybrids. Nineteen out of the 38 coconut hybrids in the first trial started to flower and produce fruits in Brazil, Jamaica and Mexico in 2.5-3.0 years after planting compared 
to the seven years it would normally take for the traditional Tall varieties to reach the fruiting stage. On the other hand, flowering was not observed in the hybrids planted in Benin, Côte d'Ivoire and Tanzania during the same period. These results suggest that the drought in Africa and the generally drier conditions in that region compared to those in Latin America and the Caribbean had a negative effect on the early flowering of the hybrids... This germplasm $\mathrm{x}$ environment interaction could be verified with the vegetative and reproductive plant measurements, and biotic and abiotic data to be gathered and analyzed in the next five years. Based on the yield projection of the 19 fruiting hybrids in their fourth year, they have the potential to produce up to 5 tons of copra (dried kernel) per hectare per year at the peak of production (at 10-12 years) compared to the 1-2 metric tons of copra produced by the traditional coconut varieties. The results of this hybrid evaluation and other hybrid performance observations around the world are presented in a forthcoming COGENT report entitled "Coconut Hybrids for Smallholders” (Batugal et al., 2005).

\section{Developing platforms for a wider $\mathbf{R} \& \mathbf{D}$ programme}

The value of coconut conservation is not maximized unless appropriate platforms are developed to deploy COGENT's conserved germplasm to promote germplasm utilization. COGENT has documented the breeding programmes of member countries (Batugal and Rao, 1998) and is currently developing a proposal for a globally coordinated coconut breeding programme. The breeding programme shall focus on the regional/global needs of COGENT member countries instead of merely those of individual countries and will adopt participatory plant breeding approach to incorporate farmers' varietal preference. Specifically, the programme initially aims to: 1) characterize conserved germplasm and farmers' varieties using morphometric and molecular techniques; 2) screen and identify ecotypes tolerant or resistant to the lethal yellowing disease and drought ; 3) improve yields for specific uses and adaptation; 4) develop varieties which are suitable for the production of high-value products from husk, fiber, shell, meat, water, wood and leaves; 5) develop technical support systems for national breeding programmes (i.e. information, pollen and embryo provision, etc.); and 6) provide a platform to promote the dissemination and use of the results of the above-mentioned coconut breeding projects to achieve socioeconomic and environmental impact. Ultimately, the programme should be able to significantly increase the choice of hybrid cultivars among coconut growing countries, by maximizing the use of available genetic resources for breeding purposes, and improve the quality of the planting materials for distribution to users or farmers.

To provide a wider R \& D platform for the utilization of COGENT's conserved germplasm and to enhance the impact of COGENT's current and future outputs, IPGRI/COGENT, the APCC and the Bureau for the Development of Research on Perennial Tropical Oil Crops or BUROTROP initiated the establishment of the Global Coconut Research for Development Program (PROCORD), a global alliance to coordinate and promote global coconut research. The formal launching of PROCORD in 2002 provided a mechanism for an integrated approach to coconut research for development initiatives worldwide as envisioned in the original priority areas of coconut research as identified by the CGIAR. In the implementation of PROCORD, the lead role for coconut genetic resources conservation and improvement, and socioeconomic and policy support were assigned to COGENT; for coconut based farming systems and crop protection, to BUROTROP; and for processing and 
Table 4. Project grants for COGENT member countries

\begin{tabular}{|c|c|c|c|}
\hline Country & No of LOAs* & $\begin{array}{l}\text { LOA funding } \\
\text { (US\$) }\end{array}$ & $\begin{array}{l}\text { National funding } \\
\text { (US\$) }\end{array}$ \\
\hline 1. Bangladesh & 17 & 83,796 & 36,770 \\
\hline 2. India & 28 & 158,475 & 150,625 \\
\hline 3. Pakistan & 2 & 14,487 & 5,000 \\
\hline 4. Sri Lanka & 26 & 137,453 & 64,835 \\
\hline 5. China & 5 & 34,373 & 28,000 \\
\hline 6. Indonesia & 26 & 179,850 & 178,672 \\
\hline 7. Malaysia & 6 & 61,800 & 103,000 \\
\hline 8. Philippines & 30 & 175,815 & 237,127 \\
\hline 9. Thailand & 9 & 70,626 & 539,343 \\
\hline 10. Vietnam & 20 & 137,356 & 83,104 \\
\hline 11. Fiji & 12 & 88,785 & 131,106 \\
\hline 12. Papua New Guinea & 20 & 111,189 & 300,371 \\
\hline 13. Samoa & 5 & 55,000 & 52,581 \\
\hline 14. Solomon Islands & 5 & 61,000 & 94,600 \\
\hline 15. Tonga & 5 & 60,200 & 24,500 \\
\hline 16. Vanuatu & 5 & 55,000 & 74,900 \\
\hline 17. Cook Islands & 1 & 11,000 & 6,875 \\
\hline 18. Kiribati & 1 & 11,000 & 6,875 \\
\hline 19. Marshall Islands & 1 & 11,000 & 6,875 \\
\hline 20. Tuvalu & 1 & 11,000 & 6,875 \\
\hline 21. Benin & 4 & 39,083 & 25,000 \\
\hline 22. Côte d' Ivoire & 10 & 310,590 & 96,566 \\
\hline 23. Tanzania & 9 & 59,833 & 49,916 \\
\hline 24. Brazil & 7 & 53,333 & 44,166 \\
\hline 25. Jamaica & 7 & 45,583 & 36,583 \\
\hline 26. Mexico & 8 & 57,333 & 48,666 \\
\hline 27. Cuba & 1 & 5,000 & 6,350 \\
\hline 28. Ghana & 1 & 1,500 & 750 \\
\hline 29. Mozambique & 1 & 11,500 & 6,000 \\
\hline 30. Portugal & 1 & 8,250 & 4,000 \\
\hline Grand total & 274 & $2,121,210$ & $2,450,031$ \\
\hline
\end{tabular}

* LOA=letter of agreement of member country with IPGRI/COGENT indicating project terms, activities and funding.

marketing, to APCC. Due to the dissolution of BUROPTROP in 2003, the Centre de
Cooperation Internationale en Researche Agronomique pour le Development (CIRAD) 
took over the functions of BUROTROP in this global research alliance, bringing its experience, expertise and resources to enhance the program.

\section{Strategic public awareness and publications}

In its effort to help disseminate strategies, technologies, public awareness materials and other information to promote coconut conservation and use, COGENT has produced and disseminated strategically selected publications (see list of cited references). It has also regularly published the COGENT Newsletter to serve as the information medium for updating members about the COGENT current and future activities; and established and maintained the COGENT webpage (http://www.ipgri.cgiar.org/networks/cogent). COGENT also published a book on technical writing, seminar presentation, public awareness and proposal preparation, and distributed this to all COGENT member countries to help coconut researchers worldwide effectively write and publish and present the results of their research (Stapleton and Batugal, 2004).

\section{Technical and financial support to member countries and partner institutions}

To support regional and global projects, COGENT and IPGRI provided funds and technical backstopping to national programs and partner institutions in 30 countries (Table 4). This enabled them to conduct 274 research projects, trainings, meetings and workshop activities in support of research with regional and global significance. For these activities, COGENT/IPGRI and its donor agencies provided $46 \%$ (US $\$ 2,121,210$ ) of the funding requirements and the national programs, $54 \%$ (US $\$ 2,450,031$ ).

\section{Conclusion}

The establishment of COGENT addressed the need for an internationally coordinated research programme on coconut genetic resources in support of the smallholder coconut farmers and the coconut industry. To ensure the sustainability of the programme, the member countries agreed to reciprocal access to germplasm, information and technology; sharing of resources to implement agreed activities; and to collaborate in solving common problems and promoting common opportunities. The public and private sectors have high expectations from COGENT to help improve coconut profitability in a sustainable manner and to provide benefits to the coconut smallholder farmers. These expectations have been partly achieved with many substantive achievements of COGENT since its establishment 12 years ago. Support of partner institutions and donors is strong. However, in the final analysis, the success of COGENT will depend mostly on the commitment and political will of the member countries to help themselves.

\section{References}

Batugal, P., Rao, V. and Bong, C. (Eds). 1998. Promoting multi-purpose uses and competitiveness of the coconut. Proceedings of Workshop, held in Chumphon Thailand on 26-29 September 1996. IPGRI-APO, Serdang, Malaysia, 190 pp.

Batugal, P.A. and Ramanatha Rao, V. (Eds.). 1998. Coconut breeding. Papers presented at a Workshop on Standardization of Coconut Breeding Research Techniques, 20-25 June 1994, Port Bouet, Côte d'Ivoire. IPGRI-APO, Serdang, Malaysia, 150 pp.

Batugal, P.A. and Engelmann, F. (Eds). 1998. Coconut embryo in vitro culture. Papers presented at a Workshop on Embryo Culture, 27-31 October 1997, Banao, Guinobatan, Albay, Philippines. IPGRIAPO, Serdang, Malaysia, 164 pp.

Batugal, P. and Oliver, J. (Eds). 2003. Poverty reduction in coconut growing communities: The Framework and Project Plan. IPGRIAPO, Serdang, Malaysia, Volume I. 337 pp.

Batugal, P. and Coronel, R. (Eds.). 2004. Poverty Reduction in Coconut Growing Communities: Mobilizing for Action. 
IPGRI-APO, Serdang, Malaysia, Volume II. 293 pp.

Batugal, P. and Oliver, J. (Eds.). 2005. Poverty Reduction in Coconut Growing Communities: Project Achievements and Impact. IPGRI-APO, Serdang, Malaysia, Volume III. $270 \mathrm{pp}$.

Batugal, P., Benigno, D. and Oliver, J. 2005. Coconut hybrids for smallholders. IPGRIAPO, Serdang, Malaysia. In press.

Engelmann, F., Batugal, P. and Oliver, J. (Eds.). 2002. Coconut Embryo in vitro Culture: Part II. IPGRI-APO, Serdang, Malaysia, 192 pp.

Eyzaguirre, P.B and Batugal, P. (Eds.) 1999. Farmer Participatory Research on Coconut Diversity: Workshop Report on Methods and Field Protocols. IPGRI-APO, Serdang, Malaysia, $120 \mathrm{pp}$.
Ikin, R. and Batugal, P. (Eds.). 2004. Germplasm Health Management for COGENT's Multi-site International Coconut Genebank. IPGRI-APO, Serdang, Malaysia, $159 \mathrm{pp}$.

Rao, V. and Batugal, P.A. (Eds.). 1998. Proceedings of the COGENT Regional Coconut Genebank Planning Workshop, 2628 February 1996, Pekanbaru, Riau, Indonesia. IPGRI-APO, Serdang, Malaysia, $115 \mathrm{pp}$.

Santos, G.A., Batugal, P.A., Othman, A., Baudouin, L. and Labouisse, J.P. (Eds.). 1996. Manual on Standardized Research Techniques in Coconut Breeding. IPGRIAPO, Serdang, Malaysia, 46 pp.

Stapleton, P., Batugal, P. and Oliver, J. (Eds.). 2004. Manual on Technical Writing, Public Awareness, Seminar Presentation and Proposal Preparation for Coconut Researchers. IPGRI-APO, Serdang, Malaysia, 119 pp. 